\title{
Article
}

Subscriber access provided by King Abdullah University of Science and Technology Library

\section{A fine-tuned Metal-Organic Framework for Autonomous Indoor Moisture Control .}

Rasha G. AbdulHalim, Prashant M. Bhatt, Youssef Belmabkhout, Aleksander Shkurenko, Karim Adil, Leonard J. Barbour, and Mohamed Eddaoudi

J. Am. Chem. Soc., Just Accepted Manuscript • DOI: 10.1021/jacs.7b04132 • Publication Date (Web): 29 Jun 2017

Downloaded from http://pubs.acs.org on July 4, 2017

\section{Just Accepted}

"Just Accepted" manuscripts have been peer-reviewed and accepted for publication. They are posted online prior to technical editing, formatting for publication and author proofing. The American Chemical Society provides "Just Accepted" as a free service to the research community to expedite the dissemination of scientific material as soon as possible after acceptance. "Just Accepted" manuscripts appear in full in PDF format accompanied by an HTML abstract. "Just Accepted" manuscripts have been fully peer reviewed, but should not be considered the official version of record. They are accessible to all readers and citable by the Digital Object Identifier (DOI®). "Just Accepted" is an optional service offered to authors. Therefore, the "Just Accepted" Web site may not include all articles that will be published in the journal. After a manuscript is technically edited and formatted, it will be removed from the "Just Accepted" Web site and published as an ASAP article. Note that technical editing may introduce minor changes to the manuscript text and/or graphics which could affect content, and all legal disclaimers and ethical guidelines that apply to the journal pertain. ACS cannot be held responsible for errors or consequences arising from the use of information contained in these "Just Accepted" manuscripts. 


\title{
A fine-tuned Metal-Organic Framework for Autonomous In- door Moisture Control
}

\author{
Rasha G. AbdulHalim, ${ }^{\dagger}$ Prashant M Bhatt, ${ }^{\dagger}$ Youssef Belmabkhout, ${ }^{\dagger}$ Aleksander Shkurenko, ${ }^{\dagger}$ Karim \\ Adil, ${ }^{\dagger}$ Leonard J. Barbour ${ }^{\dagger}$ and Mohamed Eddaoudi ${ }^{\dagger}$. \\ ${ }^{\dagger}$ King Abdullah University of Science and Technology (KAUST), Division of Physical Sciences and Engineering, Advanced \\ Membranes \& Porous Materials Center, Functional Materials Design, Discovery \& Development Research Group $\left(\mathrm{FMD}^{3}\right)$, \\ Thuwal 23955-6900, Kingdom of Saudi Arabia, Thuwal 23955-6900, Kingdom of Saudi Arabia, E-mail: mo- \\ hamed.eddaoudi@kaust.edu.sa \\ "Department of Chemistry and Polymer Science, University of Stellenbosch, Stellenbosch 7600, South Africa
}

Supporting Information Placeholder

\begin{abstract}
Conventional adsorbents, namely zeolites and silica gel, are often used to control humidity by adsorbing water; however, adsorbents capable of dual functionality of humidification and dehumidification, offering the desired control of the moisture level at room temperature, has yet to be explored. Here we report Y-shp-MOF-5, a hybrid microporous highly-connected RareEarth based metal-organic framework (MOF), with dual functionality for moisture control within the recommended range of relative humidity ( $45 \%$ to $65 \% \mathrm{RH}$ ) set by the American Society of Heating, Refrigerating, and Air-Conditioning Engineers (ASHRAE). Y-shp-MOF-5 exhibits exceptional structural integrity, robustness and unique humidity-control performance as confirmed by the large number (thousand) of conducted water vapor adsorption-desorption cycles. The retained structural integrity and the mechanism of water sorption were corroborated using in situ single crystal X-ray diffraction (SCXRD) studies. The resultant working water uptake of $0.45 \mathrm{~g} . \mathrm{g}^{-1}$ is solely regulated by a simple adjustment of the relative humidity, positioning this hydrolytically stable MOF as a prospective adsorbent for humidity control in confined spaces such as space shuttles, aircraft cabins and airconditioned buildings.
\end{abstract}

\section{INTRODUCTION}

Owing to the inventions of the contemporary age, our lifestyle has morphed from previously open-air residential and occupational environments into more enclosed air-conditioned ones, particularly in regions with extreme hot and cold weather. ${ }^{1}$ One of the most critical challenges facing engineers in indoor environments, more so in confined spaces, is regulating the escalating levels of humidity levels. ${ }^{2}$ It is to be noted that moisture accumulation, in the absence of proper control measures such as ventilation and sorbents, promotes the growth of mold, mildew and other fungi. ${ }^{3}$ Respectively, recent studies indicated that prolonged exposure to toxigenic fungi triggers high levels of allergies and infectious diseases. ${ }^{4}$ Markedly, the appropriate indoor relative humidity (RH) levels for a healthy and comfortable environment in peopled/occupied structures lies between $45 \% \mathrm{RH}$ and $65 \% \mathrm{RH}$, as recommended by the American Society of Heating, Refrigerating, and Air-Conditioning Engineers (ASHRAE). ${ }^{5}$

Of particular concern are cases of confined spaces where the humidity level needs to be maintained with limited or no access to fresh air, such as space shuttles, airplane cabins, submarines, etc. ${ }^{6,7}$ Therefore, in order to regulate humidity levels in the cabin for a safe and comfortable environment as recommended by ASHRAE, an ideal adsorbent material should swiftly adsorb water vapor as humidity levels exceed $65 \% \mathrm{RH}$ ( and desorb water vapor as humidity levels drop largely below $45 \%$ RH. ${ }^{5}$ Such a material, if available, will pave the way towards alleviating the various existing burdens imposed by currently deployed techniques per- taining to the design capacity, energy-efficiency and the overall cost.

Metal-organic frameworks (MOFs), a unique class of hybrid porous materials, have emerged as a prime contender to traditional porous materials such as zeolites and silica gels with a great prospective to address ongoing challenges pertaining to physisorption-based applications such as gas storage and separation applications. $^{8}$ Evidently, there is a distinct growing interest in these materials for swing-based adsorption applications primarily due to their exceptional porosity, chemical stability, modularity and affinity for specific probe molecules. ${ }^{9}$ Several recent studies have examined MOFs for their water adsorption properties ${ }^{10}$ showing high tolerance to water vapor, albeit only a handful showed promising potential for water adsorption related applications. ${ }^{11}$ Most importantly, these studies have revealed some of the critical and structural features that control the stability of MOFs in the presence of water vapor as well as under cyclic water adsorption measurements. ${ }^{12}$

The key to successfully design high performance MOFs for targeted applications is through implementing the molecular building block (MBB) approach. ${ }^{13}$ Our group has been actively involved in pursuing new modular approaches targeting highly-connected polynuclear rare earth (RE) carboxylate-based metal clusters. To this end, among the different approaches listed in the literature to develop hydrolytically stable MOFs; we elected to target MOFs based on the assembly of the highly-connected RE MBBs. ${ }^{14}$

In this work, we unveil a new Y-shp-MOF-5 as a unique energyefficient adsorbent with dual humidifying/dehumidifying operations in the optimal range $45 \%-65 \% \mathrm{RH}$ and an equilibrium 
water uptake and working capacity of $50 \mathrm{wt} \%$ and $45 \mathrm{wt} \%$, respectively. The observed $\mathbf{S}$-shaped water adsorption isotherm at room temperature (RT), with adsorption and desorption branches concentrated at relative humidity levels higher and lower than $50 \%$ RH respectively, is particularly beneficial in an autonomous moisture controlled swing adsorption approach, ${ }^{15}$ regulated only by altering the relative humidity between $25 \%$ and $85 \% \mathrm{RH}(8$ and 26 mbar) at RT. It is to be noted that the equilibrium uptake is determined at a specific relative humidity (water vapor pressure), while the working capacity is derived from the difference in the water equilibrium uptake between two relative humidity levels. Prominently, the Y-shp-MOF-5 adsorbent offers the capturing of moisture at a relative humidity level higher than $50 \% \mathrm{RH}$ and the subsequent release of moisture at a relative humidity level below $50 \% \mathrm{RH}$ with very high and identical working capacities, a unique feature within the ASHRAE recommendations for maintaining a comfortable environment in enclosed spaces. ${ }^{5}$

The unique adsorption properties of Y-shp-MOF-5 were studied by a combination of water adsorption and in-situ single crystal Xray diffraction (SCXRD) studies. Systematic in situ SCXRD studies, carried out under different humidity conditions, allowed us to localize the adsorbed water molecules and to gain a better understanding of the water-framework interactions governing the resultant unique water adsorption properties of Y-shp-MOF-5. The inimitable performance of Y-shp-MOF-5 for moisture control was delineated by comparing its performance with the best solid state materials, with and without $\mathbf{S}$-shaped water adsorption uptake, including MOFs, zeolites, clay and mesoporous silica. ${ }^{11 a, 16}$

\section{RESULTS AND DISSCUSION}

In our attempts to target a rare earth (RE) based shp-MOF, we chose 1,2,4,5-tetrakis(4-carboxyphenyl)benzene (BTEB), which can act as a rectangular/quadrangular organic MBB (Figure 1a). A solvothermal reaction between $\mathrm{RE}\left(\mathrm{NO}_{3}\right)_{3} \cdot \mathrm{xH}_{2} \mathrm{O}\left(\mathrm{RE}=\mathrm{Y}^{3+}\right)$ and BTEB in a N,N'-dimethylformamide (DMF) / water solution in the presence of 2-fluorobenzoic acid (2-FBA) yielded hexagonalbipyramidal shaped crystals. As anticipated, based on previous work from our group, the in situ formation of the 12-connected (12-c) RE MBB was facilitated by the addition of excess amount of 2-FBA, which acts as a modulator for the in situ formation of

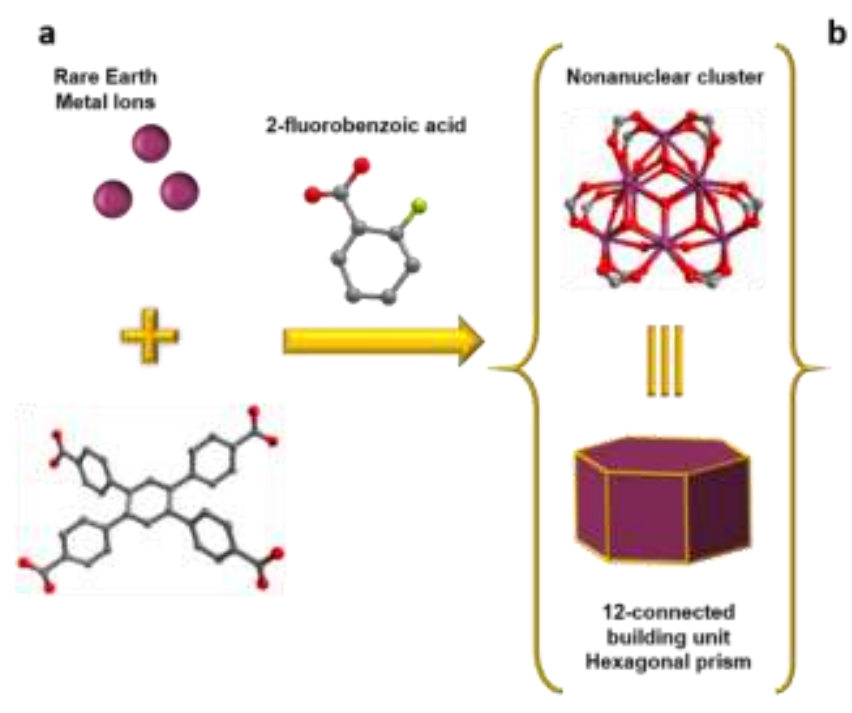

highly connected polynuclear carboxylate-based clusters. ${ }^{14 a,} \quad 14 \mathrm{i}$ The phase purity of the as-synthesized material and its stability in various solvents was confirmed by the whole profile pattern matching of powder X-ray diffraction (PXRD) patterns using the Le Bail (Figure S3, S4).

The SCXRD studies revealed that Y-shp-MOF-5 crystallizes in the hexagonal space group $P 6_{3} / m m c$ and was formulated as $\mathrm{DMA}_{3}\left[\mathrm{Y}_{9}\left(\mu_{3}-\mathrm{O}\right)_{2}\left(\mu_{3}-\mathrm{OH}\right)_{12}(\mathrm{OH})_{2}\left(\mathrm{H}_{2} \mathrm{O}\right)_{7}(\mathrm{BTEB})_{3}\right] \cdot(\text { solv })_{\mathrm{x}}$

$(\mathrm{DMA}=$ dimethylammonium cation and solv. = solvent $)$. Topological analysis of the resulting crystal structure confirmed that the obtained $(4,12)$-c MOF, based on the distinct 12-c polynuclear RE cluster $\left[\mathrm{Y}_{9}\left(\mu_{3}-\mathrm{O}\right)_{2}\left(\mu_{3}-\mathrm{OH}\right)_{12}(\mathrm{OH})_{2}\left(\mathrm{H}_{2} \mathrm{O}\right)_{7}\left(\mathrm{O}_{2} \mathrm{C}-\right)_{12}\right]$ linked through the rectangular-shaped BTEB ligand, has the expected square hexagonal-prism (shp) topology (Figures S1 and S2). It is to be mentioned that the Y-shp-MOF-5 structure is constructed from nonanuclear yttrium (III) $\left(\mathrm{Y}^{3+}\right)$ carboxylate-based clusters, enclosing nine yttrium cations $\left(\mathrm{Y}_{9}\right)$ statistically disordered over two positions with occupancy ca. 0.79 and 0.21 and arranged in a tricapped trigonal prism fashion. Six $\mathrm{Y}^{3+}$ ions coordinate to eight oxygen atoms; that is, two carboxylates of two separate ligands (BTEB), four $\mu_{3}-\mathrm{OH}$, one $\mu_{3}-\mathrm{O}$, and one water molecule or hydroxyl group. Each of the remaining three $\mathrm{Y}^{3+}$ ions coordinate to nine oxygen atoms; that is, four from carboxylates of four distinct BTEB ligands, four $\mu_{3}-\mathrm{OH}$, and one apical water molecule. The overall cluster is anionic $\left[\mathrm{Y}_{9}\left(\mu_{3}-\mathrm{O}\right)_{2}\left(\mu_{3}-\mathrm{OH}\right)_{12}(\mathrm{OH})_{2}\left(\mathrm{O}_{2} \mathrm{C}-\right)_{12}\right]^{3-}$, and the resultant overall charge of the framework is balanced by three $\mathrm{DMA}^{+}$cations generated in situ from the decomposition of DMF molecules. As depicted in Figure 1, the Y-shp-MOF-5 structure is composed of 12-c nonanuclear cluster linked via 12 carboxylates from 12 different BTEB ligands to give a 12-c MBB, hexagonal prism building unit. The Y-shp-MOF-5 structure can be viewed as a hexagonal close packing of the nonanuclear MBBs and can be further simplified as pillared hexagonal (hxl) layers; thus forming uniform triangular 1D channels with an opening of $12 \AA$ along $c$ axis. It is to be mentioned that different RE metal cation (i.e $\mathrm{Yb}^{3+}$ ) based shp-MOF-5 analogue has been isolated under similar reaction conditions (Figure S7), but herein only Yshp-MOF-5 was presented in details and intensively studied for permanent porosity and water sorption behavior. b

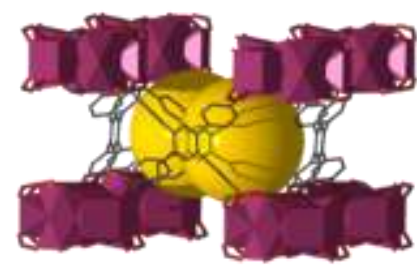

(4,12)-connected net shp net

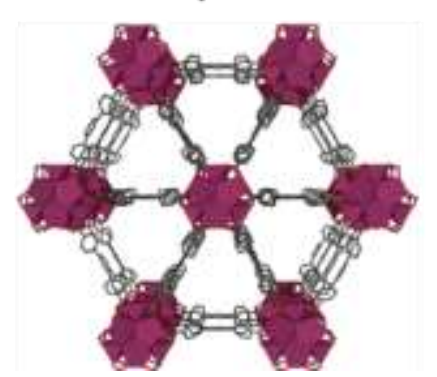

c

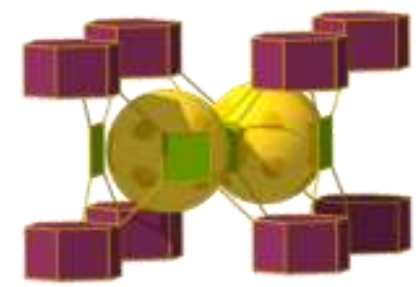

shp-a net

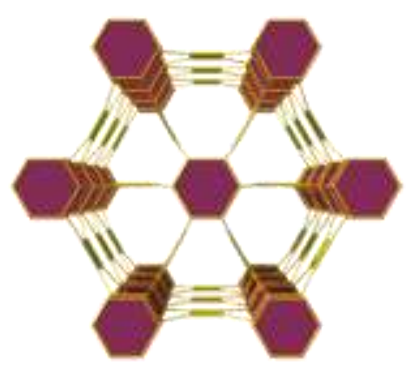

Figure 1. Schematic representation showing the combination of 12-c rare earth nonanuclear cluster in the presence of tetratopic linker BTEB (a) resulting in the formation of a 3-periodic $(4,12)$-connected Y-shp-MOF-5 (b). The combination of hexagonal prism and rectangular building blocks resulted in a MOF with shp topology, displayed as an augmented shp-a net (c). 
In order to explore the permanent porosity of the Y-shp-MOF-5 structure, acetone exchanged samples were activated by heating to $125^{\circ} \mathrm{C}$ under vacuum. Argon adsorption study at $87 \mathrm{~K}$ revealed a fully reversible Type-I isotherm, characteristic of a microporous material with permanent microporosity (Figure S16). The apparent BET surface area and the total pore volume were estimated to be $1550 \mathrm{~m}^{2} \mathrm{~g}^{-1}$ and $0.63 \mathrm{~cm}^{3} \mathrm{~g}^{-1}$, respectively, where the pore volume is in good agreement with the theoretical value derived from SCXRD data of $0.61 \mathrm{~cm}^{3} \mathrm{~g}^{-1}$. Markedly, the Y-shp-MOF-5 structure preserved its optimal porosity after heating up to $160{ }^{\circ} \mathrm{C}$ and structural integrity as confirmed by variable temperature (VT) PXRD and thermal gravimetric analysis (TGA) (Figures S8 and S10, respectively). In light of the large number of exposed open metal sites per nonanuclear cluster, ascertained from the crystal structure, we aimed to assess and evaluate the performance of the Y-shp-MOF-5 under different relative humidity levels by performing water adsorption measurements and subsequently collecting associated crystal structures under variable relative humidity conditions.

\section{Water adsorption properties of Y-shp-MOF-5}

Water vapor adsorption experiments were carried out to examine water vapor adsorption characteristics of the Y-shp-MOF-5 using a VTI-SA vapor sorption analyzer from TA Instruments (New Castle, DE, United States). The water vapor partial pressure was controlled automatically by mixing wet vapor feed with a dry $\mathrm{N}_{2}$ line; hence, $\mathrm{N}_{2}$ acts as a carrier gas for water vapor. Pre-drying of the sample was carried at $125^{\circ} \mathrm{C}$ in the presence of $\mathrm{N}_{2}$ dry carrier. The sample "dry mass" was measured under $\mathrm{N}_{2}$ and was at equilibrium $\left(25^{\circ} \mathrm{C}\right)$ before dosing water vapor progressively into the chamber. It is to be stated that the Y-shp-MOF-5 stability to water was confirmed by in situ powder X-ray diffraction (PXRD) data under different humidity conditions $(0 \%-95 \%)$ (Figure S9). The adsorption isotherms, obtained at equilibrium, were collected between $0 \% \mathrm{RH}$ and $95 \% \mathrm{RH}$ at temperatures close to ambient $\left(25^{\circ} \mathrm{C}-35^{\circ} \mathrm{C}\right)$, (Figure S11).

The water vapor adsorption isotherm of the fully activated (125 $\left.{ }^{\circ} \mathrm{C}\right)$ Y-shp-MOF-5 revealed an initial water uptake of $5 \mathrm{wt} \%$ at low $\% \mathrm{RH}(<20 \% \mathrm{RH})$, after which it plateaus until the moisture level reaches $55 \% \mathrm{RH}-60 \% \mathrm{RH}$. It is anticipated that the exposed $\mathrm{Y}^{3+}$ open metal sites serve as the primary preferable adsorption sites for water molecules at low \% RH. At higher moisture levels (above $50 \%$ RH) a steep water vapor uptake was observed as the uptake capacity of Y-shp-MOF-5 reaches $50 \mathrm{wt} \%$, followed by a plateau at $85 \%$ RH, Figure 2 (black circles). The overall water adsorption isotherm profile revealed an interesting $\mathbf{S}$ shaped (sigmoidal) adsorption and desorption branches with the full desorption completed at intermediate relative humidity $(30 \%$ $\mathrm{RH})$ and an associated total working capacity equivalent to 45 wt $\%$. The type IV-like water adsorption/desorption isotherms showed characteristic inflection points of adsorption and desorption branches correspondingly at $55 \% \mathrm{RH}$ and $45 \% \mathrm{RH}$ respectively as depicted in Figure 2. Remarkably, this unique shape of the water vapor adsorption isotherm (i.e. steep adsorption at $55 \%$ $\mathrm{RH}-60 \% \mathrm{RH}$ and a pronounced hysteresis), unusual for microporous materials, concurs with the recommended working range for the moisture level control $(40 \% \mathrm{RH}-60 \% \mathrm{RH})$, desired for the preservation of comfortable moisture levels in confined spaces and conform to the standards set by occupational health and safety, aerospace and aviation agencies nationally and internationally. 5

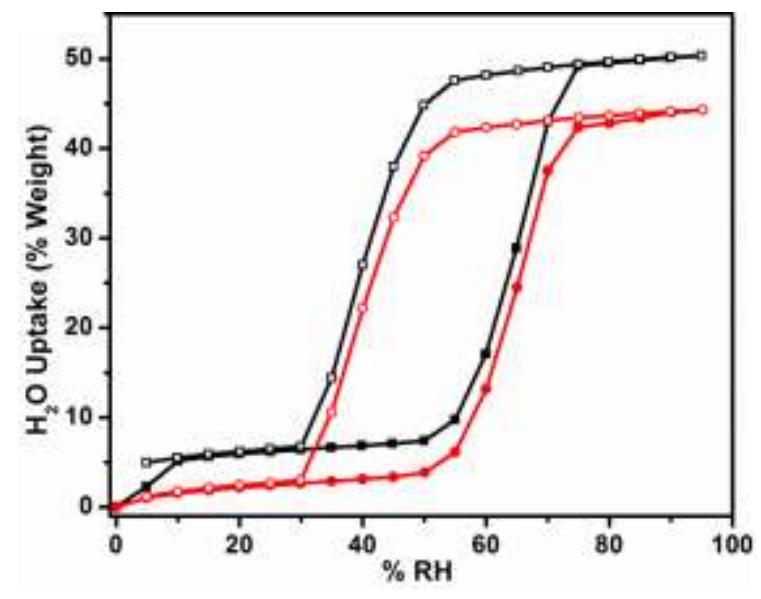

Figure 2. Water adsorption (filled symbols) and desorption (open symbols) isotherms at $25^{\circ} \mathrm{C}$ for the Y-shp-MOF-5, (- water adsorption and desorption collected after activating sample at $125^{\circ} \mathrm{C}$, (๑) water adsorption collected after reactivating sample at $25^{\circ} \mathrm{C}$.

In order to differentiate between the water molecules adsorbed on the open metal sites and those filling the remainder of the pore system, a $2^{\text {nd }}$ cycle of water vapor adsorption-desorption measurement (red circles) was carried out without any pre-activation via heating. As shown in Figure 2 (red circles), a slight decrease in the total water uptake by nearly $5 \mathrm{wt} \%$ was observed but with a preserved total water working capacity of $45 \mathrm{wt} \%$, corresponding to the total water uptake at saturation of $45 \mathrm{wt} \%$. Noticeably, the water desorption is governed solely by changes/reduction in the relative humidity, suggesting that the complete desorption of noncoordinated water molecules occurs due to the relatively weak water/framework interactions. Conversely, the coordinated water molecules to the nonanuclear cluster could not be desorbed simply by reducing the relative humidity below $30 \% \mathrm{RH}$, signifying their relatively stronger interaction with the open metal sites and the requisite for an external stimuli/driving force such as heat for their displacement. Hence, the initial step in the water vapor adsorption isotherm for the fully activated Y-shp-MOF-5 (at $125^{\circ} \mathrm{C}$ ), followed by the first plateau corresponding to a water uptake of 5 $w t \%$, is associated with the coordination of water molecules to the available open metal sites in the cluster, regarded as the most energetic sites for the initial adsorption of water molecules.

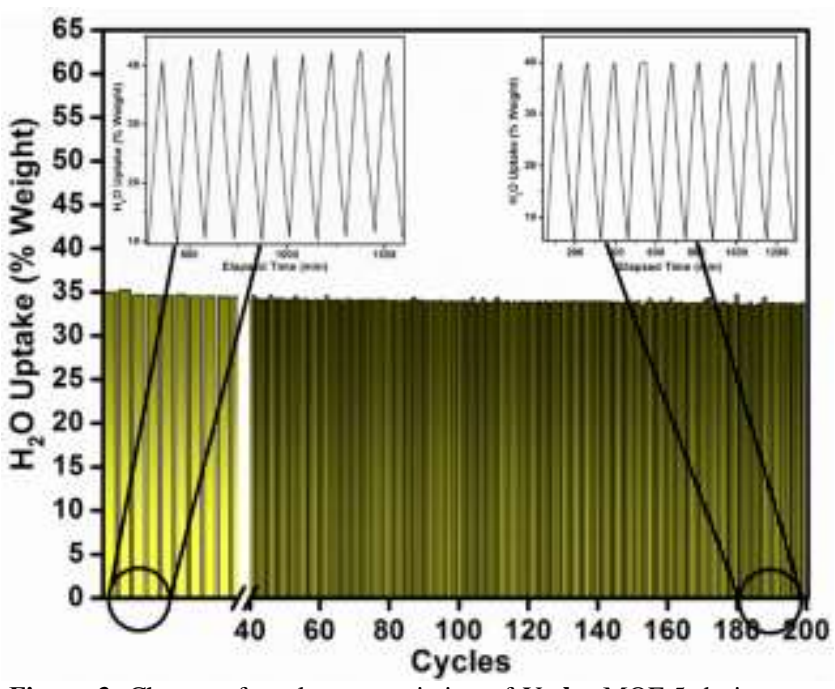

Figure 3. Change of total mass variation of Y-shp-MOF-5 during nonequilibrium adsorption and desorption over more than 200 cycles driven by the continuous change in relative humidity between $25 \% \mathrm{RH}$ and $85 \%$ RH. 
To further delineate the unique water adsorption properties associated with the Y-shp-MOF-5 and assess the effect of the temperature on the moisture-control working range, we performed additional water adsorption studies at temperatures close to ambient conditions (i.e. $30{ }^{\circ} \mathrm{C}$ and $35^{\circ} \mathrm{C}$ ). As shown in Figure $\mathrm{S} 11$, a similar behavior and isotherm shape as for the samples collected at 25 ${ }^{\circ} \mathrm{C}$ was observed but with a relatively steeper uptake at $55 \% \mathrm{RH}$ and a prompt attainment of the plateau at a lower humidity level of $65 \% \mathrm{RH}$ instead of $80 \% \mathrm{RH}$ for the samples collected at $25{ }^{\circ} \mathrm{C}$. Noticeably, the desorption of the non-coordinated water molecules, filling the pores, occurred at a relatively higher humidity level than $40 \% \mathrm{RH}$. Consequently, the Y-shp-MOF-5 associated working range for the moisture level control is slightly reduced with increasing the temperature.

In principle, the concept of moisture control devices using adsorbents implies that the same material can adsorb and desorb water vapor as it is exposed to different levels of humidity as environmental triggers. Nevertheless, most materials lack this duality, they either adsorb or desorb water vapor to the environment under specific conditions. Principally, the deployment of the Y-shpMOF-5 into moisture control devices will offer vital advantages as it starts adsorbing at $50 \% \mathrm{RH}$ and allows for the prompt release of water as humidity levels go below $45 \% \mathrm{RH}$. Using the appropriate amount of Y-shp-MOF-5/volume of space: i) the Y-shpMOF-5 adsorbent will keep adsorbing water vapor until the $\mathrm{RH}$ drops below $45 \%$ or the material reaches its saturation capacity of $50 \mathrm{wt} \%$ of water vapor; and ii) the Y-shp-MOF-5 adsorbent will start releasing the adsorbed water molecules into the atmosphere bringing the humidity back to a comfortable level, when humidity levels decrease below the predefined comfortable level of $40 \%$ RH.

Further cyclic measurements were conducted on the Y-shp-MOF5 in order to evaluate the cyclic adsorption/desorption performance of the MOF adsorbent. More than 1000 water vapor adsorption and desorption measurements, at room temperature and non-equilibrium conditions, were performed on the Y-shp-MOF-5 (Figure 3; Figure S13) with the adsorption at $85 \%$ RH (26 mbar) and the desorption at $25 \% \mathrm{RH}$ ( 8 mbar). Prior to exposing the sample to numerous cycles, acetone exchanged sample was soaked in liquid water. The stability of the sample was monitored with PXRD over the course of $24 \mathrm{~h}$ (Figure S5). The Y-shp-MOF5 showed a high and a steady cyclic water vapor adsorption operation as it maintains its working capacity in the adequate range of $35 \mathrm{wt} \%-40 \mathrm{wt} \%$. The PXRD patterns and the water adsorption isotherms collected (Figure S6 and S12 respectively) on the extensively recycled Y-shp-MOF-5 confirmed the hydrolytic stability of the Y-shp-MOF-5 and the maintenance of its structural features and original adsorption properties.

In practical conditions, an autonomous dehumidification/humidification is evidently needed when the relative humidi- ty exceeds largely $65 \% \mathrm{RH}$ (for example 70 or $80 \% \mathrm{RH}$ range) and drop largely below $45 \% \mathrm{RH}$ (for example $35-25 \% \mathrm{RH}$ range). Interestingly, even under strict relative humidity fluctuation conditions (45-65\%RH), Y-shp-MOF-5 maintains its performance with a higher working uptake of nearly $33 \mathrm{wt} \%$ (Figure S14). Furthermore, a slight change in temperature $\left( \pm 5^{\circ} \mathrm{C}\right)$ also affords changes significant changes in the water adsorption and desorption as a function of $\% \mathrm{RH}$ (Figure S11). This temperature effect was employed to perform cyclic adsorption-desorption under a constraint and narrower humidity range of $50-60 \% \mathrm{RH}$; precisely theadsorption was performed at $60 \% \mathrm{RH}$ and $20{ }^{\circ} \mathrm{C}$, while desorption was carried out at $50 \% \mathrm{RH}$ and $30{ }^{\circ} \mathrm{C}$ (Figure S15).

In order to illustrate the uniqueness of Y-shp-MOF-5 for moisture control, we selected a wide range of porous materials from the literature $^{11 a, 16-17}$ and compared their respective reported working water-vapor capacities from the adsorption and desorption branches to the corresponding values for Y-shp-MOF-5 (Table S1). According to scrutinized technical requirement for indoor moisture control, a suitable material for moisture control related applications should exhibit the following features: (i) S-shaped water vapor adsorption isotherms with adsorption and desorption branches separated in the $40-60 \% \mathrm{RH}$ range and (ii) high water vapor uptake from the adsorption branch between $40 \%$ and $60 \%$ $\mathrm{RH}$. These features reflect (a) the requirement of a specific adsorption-desorption shape and (b) the optimal working range with respect to \% RH (water vapor pressure) gradient between adsorption and desorption, at isothermal conditions, to ensure suitable adsorption swing for moisture control operations. Figure 4 shows that the selected MOFs and other porous materials, based on their outstanding performance (Table S1) in water sorption studies, could be categorized based on their dehumidification trigger point and working range. The dehumidification trigger point is herein defined as the pressure at which pore filling starts. Accordingly, most of the MOFs as well as clays could be classified as Desiccants $(\% \mathrm{RH}<40)$, while others as Highly Hydrophobic (\% RH > $65)$. Further analysis showed that MCM-41 operate in the working range of $48<\% \mathrm{RH}>65$ (blue bars reflecting working range for Cycle 1, Figure 4) close to the ASHRAE requisite range ( $40<\%$ $\mathrm{RH}>60)$ in the first cycle, nevertheless this working range was shifted and reduced considerably $(48<\% \mathrm{RH}>52)$ in the second adsorption-desorption cycle (orange bars reflecting working range for Cycle 2, Figure 4). Delightfully, upon extensive recycling at RT, Y-shp-MOF-5 retained an invariable working range (black bars reflecting working range for Cycle 1/ Cycle 2, Figure 4) within the ASHRAE requisite range and showed a unique combination of high, steady and consistent adsorption uptake and release. Based on this extensive study, Y-shp-MOF-5 can be regarded as the most suitable adsorbent for moisture control operations, in contrast to various water vapor adsorbents reported to date. 


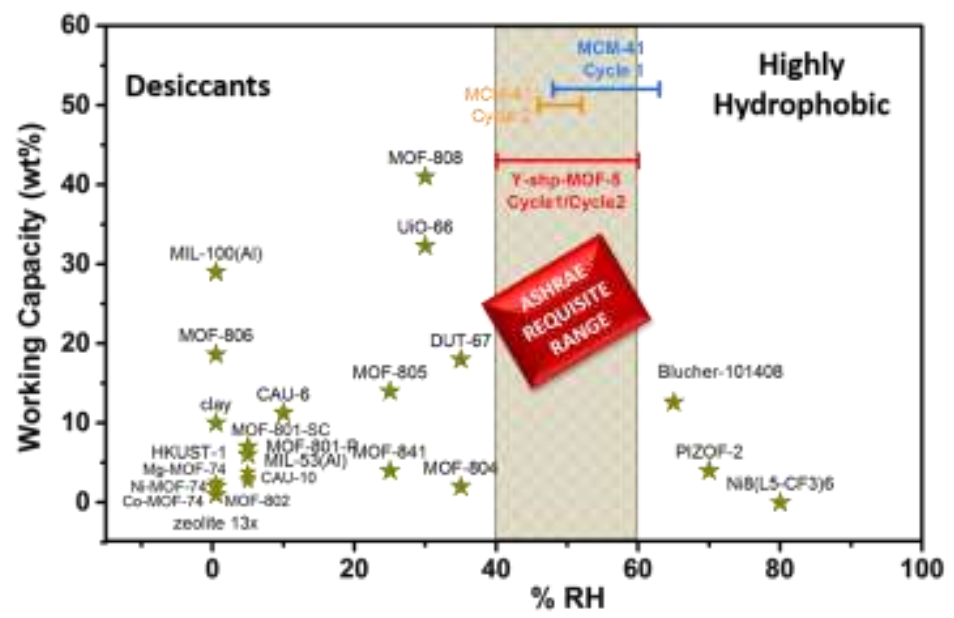

Figure 4. Working water vapor capacity in the 30-75\% RH range for water stable MOFs and other representative materials, plotted with respect to their dehumidification trigger point*. Based on dehumidification trigger point, materials could be classified as Desiccants (\% RH < 40\%), Highly hydrophobic $(\% \mathrm{RH}>60)$ and ideal for moisture control as set by ASHRAE $(40<\% \mathrm{RH}<60)$. Blue and orange bars represent working ranges of MCM-41 corresponding to Cycles 1 and 2, respectively. Red bar represents the overlapping of working range after Cycle 1 and 2 for the Y-shp-MOF-5. *point at which dehumidification starts

\section{In situ SCXRD study on the Y-shp-MOF-5 at different humid- ity level}

To gain a better insight and elucidate the mechanism governing this unique water vapor adsorption-desorption behavior, in situ SCXRD measurements were carried out on crystals exposed to various relative humidity levels (Figure 5). SCXRD data collected for the guest-free $(0 \% \mathrm{RH}) \mathrm{Y}$-shp-MOF-5 structure and the corresponding ones at $22 \% \mathrm{RH}$ and $100 \% \mathrm{RH}$ showed clearly that the crystal structure remained intact when exposed to different water vapor partial pressures. Prior to studying the preferred water adsorption sites, we collected diffraction data for a crystal mounted in an environmental gas-cell and evacuated in situ under dynamic vacuum at $125{ }^{\circ} \mathrm{C}$ for 12 hours (2). Certainly, no significant residual electron density was found in the difference Fourier maps in the pores or around the cluster, Figure S18-a, indicating the anticipated removal of the coordinated water molecules as well as the absence of free guest water molecules into the pore system and confirming the presence of at least three exposed open metal sites per RE cluster. In addition, thermal parameters associated to the $\mathrm{O}$-atoms at the axial positions suggest that hydroxyl groups coordinate to the cluster. Subsequently, the fully activated crystal was exposed to $22 \% \mathrm{RH}(3)$ and $100 \% \mathrm{RH}(4)$ by using saturated potassium acetate solution and a drop of water respectively. After $24 \mathrm{~h}$ equilibration, new set of data were collected 3 and 4 . Crystallographic analysis of $\mathbf{3}$ revealed that the open metal sites present in $\mathbf{2}$ are now fully occupied by water molecules. Diffuse electron density around the cluster suggested the presence of some water molecules hydrogen bonded with the hydroxyl groups of the cluster (Figure S18, b). In 4, exposed to $100 \% \mathrm{RH}$ at $25{ }^{\circ} \mathrm{C}$, apart from water molecules and electron density observed in $\mathbf{3}$, considerable diffused electron density was observed in the channels and the most ordered water molecules were localized (Figure S18, c). The partial order of the water molecules at higher relative humidity was also supported by the PXRD data (Figure S9). Nevertheless, we were unable to crystallographically model most of the observed electron density due to the non-ordered nature of the adsorbed water molecules in the pore system of the Y-shp-MOF5 .

As expected, SCXRD experiments (Figure 5) confirmed that the MOF framework remains unaltered when exposed to water and corroborate the hydrolytic stability of the Y-shp-MOF-5. Pertinently, the shape of the water vapor adsorption isotherm only reflects the water adsorption in distinct energetic sites. First at low pressure, water molecules are primarily adsorbed on the exposed open metal sites. The initial $5 \mathrm{wt} \%$ water uptake seen in Figure 2 (black circles) is equivalent to eight water molecules, which accounts to water molecules coordinating to open metal sites on the nonanulcear cluster and hydrogen bonded with the exposed hydroxyl groups of the nonanulcear cluster. The saturation of all open metal sites occurred at a $10 \% \mathrm{RH}$ followed by a steady uptake (at $\approx 5 \mathrm{wt} \%$ ) up to $50 \% \mathrm{RH}$. The unnoticeable additional water uptake below 50\% RH indicates the low affinity of water to the Y-shp-MOF-5 surface due plausibly to the hydrophobicity of the organic ligand; suggesting the necessity of a higher driving force for additional water adsorption, i.e., a relatively higher water vapor pressure will prompt further adsorption of water molecules into the available channels and consequently reaching full saturation at $70 \% \mathrm{RH}$ with a $50 \mathrm{wt} \%$ uptake.

The characteristic $\mathbf{S}$-shape adsorption isotherm and the occurrence of a wide hysteresis-like loop are highly unusual for microporous materials; it is more common in mesoporous materials, where the hysteresis reflects the irreversibility due to capillary condensation. In our attempt to explain the unusual hysteresis loop observed in the microporous Y-shp-MOF-5 adsorbent, we referred to the mechanism of water adsorption on microporous activated carbon proposed by Dubinin and Serpinsky (DS). ${ }^{18}$ Their interpretation of the shape of the experimental isotherms was based on the interactions between water molecules with either pure carbon or oxygencontaining surface species. According to DS theory, water molecules were initially adsorbed on primary adsorption centers, i.e. oxygen groups, then followed by the adsorption of more water molecules as they formed new hydrogen bonds with the adsorbed molecules at the primary binding sites. Finally, these secondary sites acted as nuclei for the formation of larger water clusters at higher relative humidity; eventually these clusters built sufficiently high dispersion energy to migrate into the pores and connect across the pore system forming superclusters allowing for water condensation.

Based on the DS theory, the unique behavior of water adsorption observed for the Y-shp-MOF-5 can be explained as follows: The open metal sites of Y-shp-MOF-5 and the exposed hydroxyl groups in the cluster act as primary adsorption sites for water molecules, via coordination or hydrogen bonding, due to their 
high affinity for water molecules and this was reflected by the initial adsorption of water molecules ( $5 \mathrm{wt} \%-6 \mathrm{wt} \%)$ at very low $\% \mathrm{RH}(<10 \% \mathrm{RH})$. After the first water adsorption step, the material practically does not adsorb any additional water molecules until $50 \% \mathrm{RH}$. As the water vapor pressure progressively increases, water clusters start growing until these clusters build enough dispersive energy to sustain inside the pores. This is plausibly occurring at $50 \% \mathrm{RH}$ for the Y-shp-MOF-5, manifested by the steep uptake where energetically favorable water clusters form on secondary sites via hydrogen bonding between water molecules, ultimately leading to instant pore filling as the clusters connect across the pore system to form superclusters. On the other hand, as observed in Figure 2, at $25^{\circ} \mathrm{C}$ and below $75 \%$, the desorption branch curve does not trace the adsorption branch (goes over the adsorption curve), due to the presence of the superclusters in the pores. In fact, in order for the water molecules to escape from the pore system, a driving force is needed (i.e. reducing $\mathrm{RH}$ to $45 \%$ for Y-shp-MOF-5) to dissociate the superclusters into smaller clusters $^{19}$ (having weaker dispersive forces); hence promoting the progressive desorption of the water molecules from the pores while the coordinated water molecules to the open metal sites remain adsorbed.

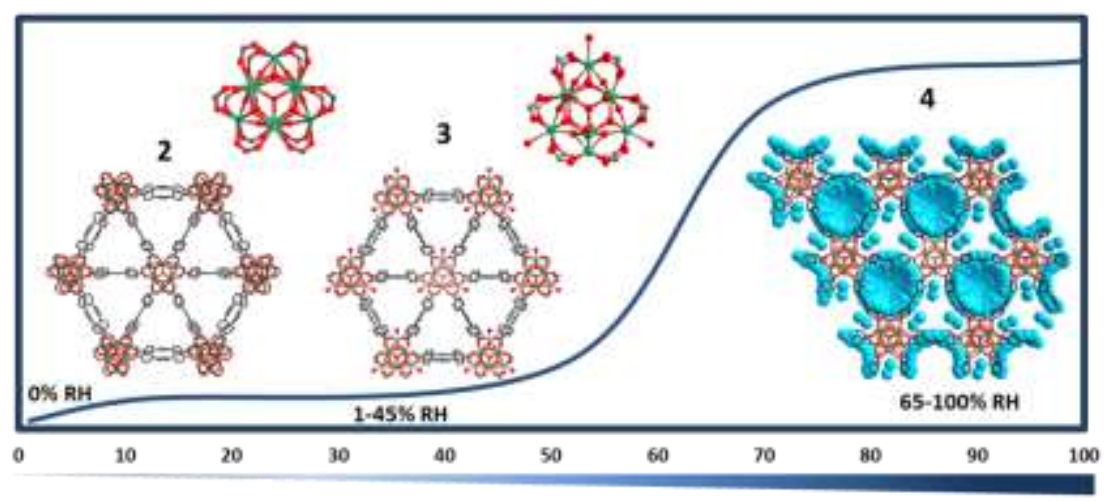

Figure 5. SCXRD revealing adsorption sites for water molecules in Y-shp-MOF-5 as exposed to elevated relative humidity. For 2, at 0\% RH, no water molecules observed (far left); for 3, between $10 \% \mathrm{RH}$ to $45 \% \mathrm{RH}$ water molecules occupying open metal sites (middle); for $\mathbf{4}$, above $65 \%$ RH water molecules occupying triangular channels.

\section{CONCLUSIONS}

In summary, we synthesized a new hydrolytically stable microporous RE based MOF with a rare shp topology. The resultant Y-shp-MOF-5 is observed to exhibit a distinctive water vapor adsorption properties in contrast to other microporous MOF materials. We have evaluated other porous solids and classified them based on their dehumidification trigger point and working range. Markedly, only Y-shp-MOF-5 and MCM-41 could be used as adsorbents in moisture control applications based on their working range. However, upon ambient conditions regeneration, MCM-41 working range shifts and reduces considerably while Yshp-MOF-5 maintains the ASHRAE requisite range even after extensive cycling. As a result, the combination of the steep adsorption instigated at around $55 \% \mathrm{RH}-60 \% \mathrm{RH}$, associated with the growth of water clusters, and the shifted desorption to $45 \%$ RH makes the Y-shp-MOF-5 an ideal adsorbent for humidity triggered water capture and release systems for adsorption based moisture-controlled processes.

Appositely, Y-shp-MOF-5 maintains its structural integrity and distinctive performance over more than 1000 moisture adsorptiondesorption cycles in the ideal range of application with a water vapor working uptake between $35 \mathrm{wt} \%-40 \mathrm{wt} \%$. These unique features, high durability and robustness, give the Y-shp-MOF-5 a clear-cut advantage over other water vapor adsorbents in general and MOFs for moisture control indoor or in confined spaces like aircrafts and submarines. Most importantly, we showed that the Y-shp-MOF-5 can adsorb and desorb large amount of water, within the ideal ASHRAE requisite range $(40<\% \mathrm{RH}>60)$, just by simply adjusting the relative humidity (water vapor pressure) at ambient temperature; affirming the prospective to deploy the Yshp-MOF-5 in energy-efficient autonomous moisture control systems. Based on these findings, further work is in progress to investigate the applicability of the Y-shp-MOF-5 in combined adsorption desalination and adsorption-based heat pump applications driven mainly by pressure swing.

\section{EXPERIMENTAL SECTION}

Materials and Methods. High resolution dynamic thermal gravimetric analysis (TGA) were performed under a continuous $\mathrm{N}_{2}$ flow $(25 \mathrm{ml} / \mathrm{min})$ with a heating rate of $1{ }^{\circ} \mathrm{C} / \mathrm{min}$ using a hi-res TGA Q500 thermal gravimetric analyzer. Low pressure gas sorption measurements were performed on a fully automated micropore gas analyzer 3Flex Analyzer (Micromeritics Instruments) at relative pressures up to $1 \mathrm{~atm}$. The powder X-ray diffraction patterns, the variable-temperature and variable-humidity powder X-ray diffraction patterns (VT-PXRD and VH-PXRD) were collected over the $2 \theta$ range $4-40^{\circ}$ on a high resolution PANalytical X'Pert MPD-PRO X-ray diffractometer with $\mathrm{Cu} K \alpha_{1}$ radiation $(\lambda$ $=1.5406 \AA, 45 \mathrm{kV} / 40 \mathrm{~mA}$ ) equipped with an Anton-Parr $\mathrm{CHC}_{+}$ variable-temperature stage, with a scan speed of $1 \% \mathrm{~min}$ and a step size of $0.03^{\circ}$ in $2 \theta$. The sample was placed under vacuum during analysis and held at the designated temperatures for at least $20 \mathrm{~min}$ between each scan. Variable-humidity PXRD (VHPXRD) pattern measurements were collected on a PANalytical X'Pert MPD-PRO X-ray diffractometer with $\mathrm{Cu} K \alpha_{1}$ radiation $(\lambda$ $=1.5406 \AA, 45 \mathrm{kV} / 40 \mathrm{~mA}$ ) equipped with Anton-Parr $\mathrm{CHC}_{+}$variable-temperature stage with a scan speed of $1 \%$ min and a step size of $0.03^{\circ}$ in $2 \theta$ connected to a Modulator Humidity Generator MHG-32 to regulate humidity between $0 \%$ and $90 \%$ RH. Samples were held at the designated relative humidity levels for at least one hour between each scan. Single-crystal X-ray diffraction data were collected using (1) an X8 Prospector APEX2 CCD diffrac- 
tometer $(\mathrm{Cu} K \alpha \lambda=1.54178 \AA$ ) and (2) Bruker Apex 2 DUO CCD diffractometer with a multilayer monochromator (Mo $K \alpha \lambda=$ $0.71073 \AA$ ). Water adsorption measurements were carried out at different temperatures close to ambient $\left(25^{\circ} \mathrm{C}-45{ }^{\circ} \mathrm{C}\right)$ using a VTI-SA vapor sorption analyzer from TA Instruments (New Castle, DE, United States).

\section{Synthesis of Compounds.}

Preparation of Y-shp-MOF-5:To a $20 \mathrm{ml}$ glass scintillation vial containing BTEB $(6.7 \mathrm{mg}, 0.012 \mathrm{mmol})$ dissolved in $0.5 \mathrm{ml} \mathrm{DMF}$, a $0.5 \mathrm{ml} 0.068 \mathrm{M} \mathrm{Y}\left(\mathrm{NO}_{3}\right)_{3} \cdot 6 \mathrm{H}_{2} \mathrm{O}$ in DMF $(0.034 \mathrm{mmol})$. To this $2.01 \mathrm{ml} 4 \mathrm{M}$ 2-fluorobenzoic acid $(8.04 \mathrm{mmol})$ in DMF and 0.75 $\mathrm{ml} \mathrm{H}_{2} \mathrm{O}$ were added. The vial was sealed and placed into a preheated oven at $105^{\circ} \mathrm{C}$ for $24 \mathrm{~h}$. Colorless hexagonal-bipyramidal crystals were obtained.

Preparation of $Y$ b-shp-MOF-5:To a $20 \mathrm{ml}$ glass scintillation vial containing BTEB $(6.7 \mathrm{mg}, 0.012 \mathrm{mmol})$ dissolved in $0.5 \mathrm{ml} \mathrm{DMF}$, a $0.5 \mathrm{ml} 0.068 \mathrm{M} \mathrm{Yb}\left(\mathrm{NO}_{3}\right)_{3} \cdot 6 \mathrm{H}_{2} \mathrm{O}$ in DMF $(0.034 \mathrm{mmol})$. To this $2.01 \mathrm{ml} 4 \mathrm{M}$ 2-fluorobenzoic acid $(8.04 \mathrm{mmol})$ in DMF, $0.75 \mathrm{ml}$ $\mathrm{H}_{2} \mathrm{O}$ and $0.1 \mathrm{ml} \mathrm{HNO}_{3}(3.5 \mathrm{M})$ was added. The vial was sealed and placed into a preheated oven at $105^{\circ} \mathrm{C}$ for $48 \mathrm{~h}$. Colorless hexagonal bipyramidal crystals were obtained.

\section{ASSOCIATED CONTENT}

\section{Supporting Information}

PXRD, TGA, additional structural figures, water sorption data, gas sorption data and single-crystal X-ray diffraction data (CIF). This material is available free of charge via the Internet at http://pubs.acs.org

\section{AUTHOR INFORMATION}

\section{Corresponding Author}

mohamed.eddaoudi@kaust.edu.sa

\section{Notes}

The authors declare no competing financial interests.

\section{ACKNOWLEDGMENT}

Research reported in this publication was supported by King Abdullah University of Science and Technology (KAUST).

\section{REFERENCES}

(1). Engström, L.-M. Food Nutr. Res. 2004, 48, 108-113. (2). Arundel, A. V.; Sterling, E. M.; Biggin, J. H.; Sterling, T. D. Environ. Health Perspect. 1986, 65, 351-361.

(3). Pirhonen, I.; Nevalainen, A.; Husman, T.; Pekkanen, J. Eur. Respir. J. 1996, 9, 2618-2622.

(4). Kuhn, D. M.; Ghannoum, M. A. Clin. Microbiol. Rev. 2003, 16, 144-172.

(5). ASHRAE, Ventilation for acceptable indoor air quality. American Society of Heating, Refrigerating, and Air Conditioning Engineers (ANSI/ASHRAE Standard 62.1-2010): Atlanta, GA., 2010.

(6). Grinshpun, S. A.; Adhikari, A.; Honda, T.; Kim, K. Y.; Toivola, M.; Ramchander Rao, K. S.; Reponen, T. Environ. Sci. Technol. 2007, 41, 606-612.
(7). Nagda, N. L.; Rector, H. E.; Li, Z.; Space, D. R., Aircraft Cabin Air Quality: A Critical Review of Past Monitoring Studies. Air Quality and Comfort in Airliner Cabins, ASTM STP 1393 ed.; American Society for Testing and Materials: West Conshohocken, PA, 2000.

(8). (a) Alezi, D.; Belmabkhout, Y.; Suyetin, M.; Bhatt, P. M.; Weselinski, L. J.; Solovyeva, V.; Adil, K.; Spanopoulos, I.; Trikalitis, P. N.; Emwas, A. H.; Eddaoudi, M. J Am Chem Soc 2015, 137, 13308-18; (b) Furukawa, H.; Cordova, K. E.; O'Keeffe, M.; Yaghi, O. M. Science 2013 , 341, 1230444; (c) Shekhah, O.; Belmabkhout, Y.; Chen, Z.; Guillerm, V.; Cairns, A.; Adil, K.; Eddaoudi, M. Nat Commun 2014, 5.

(9). (a) Guillerm, V.; Kim, D.; Eubank, J. F.; Luebke, R.; Liu, X.; Adil, K.; Lah, M. S.; Eddaoudi, M. Chem Soc Rev 2014, 43, 6141-72; (b) Furukawa, H.; Ko, N.; Go, Y. B.; Aratani, N.; Choi, S. B.; Choi, E.; Yazaydin, A. O.; Snurr, R. Q.; O'Keeffe, M.; Kim, J.; Yaghi, O. M. Science 2010, 329, 424-428; (c) Eddaoudi, M.; Moler, D. B.; Li, H.; Chen, B.; Reineke, T. M.; O'Keeffe, M.; Yaghi, O. M. Acc. Chem. Res. 2001, 34, 319.

(10). (a) Yang, Q.; Vaesen, S.; Ragon, F.; Wiersum, A. D.; Wu, D.; Lago, A.; Devic, T.; Martineau, C.; Taulelle, F.; Llewellyn, P. L.; Jobic, H.; Zhong, C.; Serre, C.; De Weireld, G.; Maurin, G. Angew. Chem. Int. Ed. 2013, 52, 10316-10320; (b) Küsgens, P.; Rose, M.; Senkovska, I.; Fröde, H.; Henschel, A.; Siegle, S.; Kaskel, S. Microporous Mesoporous Mater. 2009, 120, 325-330; (c) Akiyama, G.; Matsuda, R.; Kitagawa, S. Chem. Lett. 2010, 39, 360-361. (11). (a) Furukawa, H.; Gandara, F.; Zhang, Y. B.; Jiang, J.; Queen, W. L.; Hudson, M. R.; Yaghi, O. M. J Am Chem Soc 2014, 136, 4369-81; (b) Seo, Y. K.; Yoon, J. W.; Lee, J. S.; Hwang, Y. K.; Jun, C. H.; Chang, J. S.; Wuttke, S.; Bazin, P.; Vimont, A.; Daturi, M.; Bourrelly, S.; Llewellyn, P. L.; Horcajada, P.; Serre, C.; Ferey, G. Adv Mater 2012, 24, 806-10; (c) Henninger, S. K.; Jeremias, F.; Kummer, H.; Janiak, C. Eur. J. Inorg. Chem. 2012, 2012, 2625-2634; (d) Frohlich, D.; Henninger, S. K.; Janiak, C. Dalton Trans 2014, 43, 15300-4; (e) Ehrenmann, J.; Henninger, S. K.; Janiak, C. Eur. J. Inorg. Chem. 2011, 2011, 471-474; (f) Kizzie, A. C.; Wong-Foy, A. G.; Matzger, A. J. Langmuir 2011, 27, 6368-73; (g) Cadiau, A.; Lee, J. S.; Damasceno Borges, D.; Fabry, P.; Devic, T.; Wharmby, M. T.; Martineau, C.; Foucher, D.; Taulelle, F.; Jun, C. H.; Hwang, Y. K.; Stock, N.; De Lange, M. F.; Kapteijn, F.; Gascon, J.; Maurin, G.; Chang, J. S.; Serre, C. Adv Mater 2015, 27, 4775-80; (h) Kim, H.; Yang, S.; Rao, S. R.; Narayanan, S.; Kapustin, E. A.; Furukawa, H.; Umans, A. S.; Yaghi, O. M.; Wang, E. N. Science 2017, 356, 430-434. (12). (a) Canivet, J.; Fateeva, A.; Guo, Y.; Coasne, B.; Farrusseng, D. Chem Soc Rev 2014, 43, 5594-617; (b) Burtch, N. C.; Jasuja, H.; Walton, K. S. Chem. Rev. 2014, 114, 10575-612.

(13). Kitagawa, S.; Kitaura, R.; Noro, S. Angew. Chem. Int. Ed. 2004, 43, 2334-75.

(14). (a) Xue, D. X.; Cairns, A. J.; Belmabkhout, Y.; Wojtas, L.; Liu, Y.; Alkordi, M. H.; Eddaoudi, M. J. Am. Chem. Soc. 2013, 135, 7660-7; (b) Guillerm, V.; 
Weselinski, L.; Belmabkhout, Y.; Cairns, A. J.; D'Elia, V.; Wojtas, L.; Adil, K.; Eddaoudi, M. Nat Chem 2014, 6, 67380; (c) Alezi, D.; Peedikakkal, A. M. P.; Weseliński, Ł. J.; Guillerm, V.; Belmabkhout, Y.; Cairns, A. J.; Chen, Z.; Wojtas, Ł.; Eddaoudi, M. J. Am. Chem. Soc. 2015, 137, 5421-5430; (d) Luebke, R.; Belmabkhout, Y.; Weseliński, Ł. J.; Cairns, A. J.; Alkordi, M.; Norton, G.; Wojtas, L.; Adil, K.; Eddaoudi, M. Chem Sci 2013, 6, 4095-4102; (e) Xue, D. X.; Belmabkhout, Y.; Shekhah, O.; Jiang, H.; Adil, K.; Cairns, A. J.; Eddaoudi, M. J Am Chem Soc 2015, 137, 5034-40; (f) Assen, A. H.; Belmabkhout, Y.; Adil, K.; Bhatt, P. M.; Xue, D. X.; Jiang, H.; Eddaoudi, M. Angew. Chem. Int. Ed. 2015; 54, 14353-14358 (g) Morris, W.; Volosskiy, B.; Demir, S.; Gandara, F.; McGrier, P. L.; Furukawa, H.; Cascio, D.; Stoddart, J. F.; Yaghi, O. M. Inorg Chem 2012, 51, 6443-5; (h) Feng, D.; Gu, Z. Y.; Chen, Y. P.; Park, J.; Wei, Z.; Sun, Y.; Bosch, M.; Yuan, S.; Zhou, H. C. J Am Chem Soc 2014, 136, 17714-7; (i) Chen, Z.; Weseliński, Ł. J.; Adil, K.; Belmabkhout, Y.;
Shkurenko, A.; Jiang, H.; Bhatt, P. M.; Guillerm, V.; Dauzon, E.; Xue, D.-X.; O'Keeffe, M.; Eddaoudi, M. J. Am. Chem. Soc. 2017, 139, 3265-3274.

(15). Wang, T.; Lackner, K. S.; Wright, A. Environ Sci Technol 2011, 45, 6670-5.

(16). (a) Hatch, C. D.; Wiese, J. S.; Crane, C. C.; Harris, K. J.; Kloss, H. G.; Baltrusaitis, J. Langmuir 2012, 28, 17901803; (b) Padial, N. M.; Quartapelle Procopio, E.; Montoro, C.; López, E.; Oltra, J. E.; Colombo, V.; Maspero, A.; Masciocchi, N.; Galli, S.; Senkovska, I.; Kaskel, S.; Barea, E.; Navarro, J. A. R. Angew. Chem. Int. Ed. 2013, 52, 8290-8294.

(17). SorbentSystems Dessicant Chart Comparison. https://www.sorbentsystems.com/desiccants_charts.html\#fi gure2 (accessed 1609 25).

(18). Do, D. D.; Do, H. D. Carbon 2000, 38, 767-773.

(19). Do, D. D.; Junpirom, S.; Do, H. D. Carbon 2009, 47, 1466-1473. 


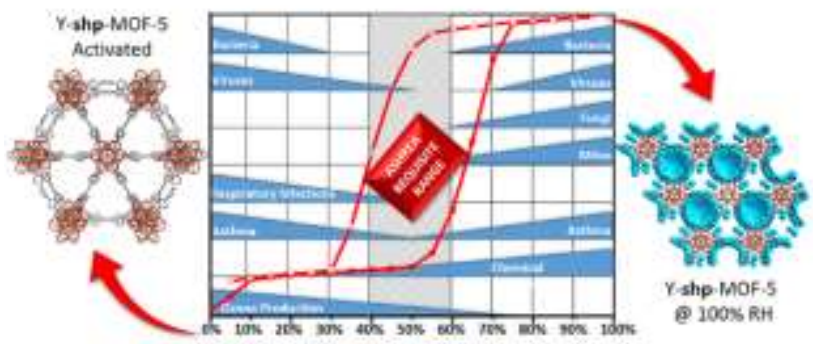

